UDC 123.1

LBC 87.5

\title{
REFLECTION OF THE PHENOMENON OF FREEDOM IN CATEGORIES OF CRIMINAL LAW
}

\author{
Lyubov V. Lobanova \\ Volgograd State University, Volgograd, Russian Federation \\ Alexey P. Rozhnov \\ Volgograd State University, Volgograd, Russian Federation \\ Larisa N. Larionova \\ Volgograd State University, Volgograd, Russian Federation
}

\begin{abstract}
Freedom is a natural-legal value that makes up the essence of human nature and therefore it is innate. The latter determines a research interest in how freedom in all the variety of its essential features (freedom, choice, freedom of will, boundaries of freedom, independence of an individual, etc.) manifests itself in various forms of human life, including such a segment of positive law as criminal law. Being a guarantee of personality development, allowing it to break out of the circle of diverse social connections determining its behavior, freedom, nevertheless, has certain limits of its activity. The establishment of these boundaries is necessary to ensure the freedom of each person so that the freedom of one does not become the non-freedom of the other. These boundaries are set by all positive law, including criminal law. Hence, ensuring personal freedom should be the goal of criminal law-making and criminalization of dangerous forms of human behavior. However, ensuring freedom and educating a person in the spirit of a conscious and responsible choice is not the same thing. Therefore, mixing or combining these goals in criminal law is contrary to the goals of legal regulation and testifies to the right of paternalism, incompatible with the purpose and possibilities of law in general and criminal law in particular. The realization of freedom outside is the act of a person, which is the result of a conscious choice of one of the many options for the behavior of the individual as a rational being. Consequently, a set of conscious behaviors themselves, as well as criminal ones which have not gone beyond the limits of its mental activity, i.e. not taken place in the act, under no circumstances can be declared criminal. Hence, the authors once again emphasize that the occurrence and revealing intent to commit a crime are indifferent to the criminal law and are outside its scope. Freedom as a choice embodied in a person's deed is ensured by the establishment of norms in criminal law aimed at protecting external freedom. The latter, through criminal law, legally guarantees an individual the possibility of unimpeded movement, choice of place of residence, place of stay, acting in this capacity as a prerequisite for the realization of freedom in its I anthropological dimension. But human freedom manifests itself most vividly as a sign of guilt, which is an indispensable sign of any corpus delicti - the only basis for criminal liability and, therefore, the most serious personality restrictions. It should be noted that the principle of guilt (liability for guilt) is en shrined in the criminal law (Article 5) among the fundamental principles of the industry. Subject to Art. 5 of the Criminal Code $\therefore$ of the Russian Federation criminal liability is possible only if there is guilt as a conscious-volitional attitude of a person to the deed and its consequences.

Key words: freedom, freedom of choice, free will, criminal law, socially dangerous behavior, criminalization,
\end{abstract}




\title{
ОТРАЖЕНИЕ ФЕНОМЕНА СВОБОДЫ В КАТЕГОРИЯХ УГОЛОВНОГО ПРАВА
}

\author{
Любовь Валентиновна Лобанова \\ Волгоградский государственный университет, г. Волгоград, Российская Федерация
}

Алексей Петрович Рожнов

Волгоградский государственный университет, г. Волгоград, Российская Федерация

\section{Лариса Николаевна Ларионова}

Волгоградский государственный университет, г. Волгоград, Российская Федерация

\begin{abstract}
Аннотация. Свобода представляет собой естественно-правовую ценность, составляющую сущность природы человека и потому присущую ему от рождения. Последнее определяет исследовательский интерес к тому, как свобода во всем многообразии своих существенных признаков (свобода выбора, свобода воли, границы свободы, независимость личности и проч.) проявляет себя в различных формах человеческого бытия, включая и такой сегмент позитивного права, как уголовный закон. Будучи залогом развития личности, позволяющим ей вырываться из круга детерминирующих ее поведение многообразных социальных связей, свобода тем не менее имеет определенные границы своей активности. Установление этих границ необходимо для обеспечения свободы каждой личности, чтобы свобода одного не стала несвободой другого. Данные границы задаются всем позитивным правом, включая и уголовное. Отсюда обеспечение свободы личности должно быть целью уголовного правотворчества и криминализации опасных форм человеческого поведения. При этом обеспечение свободы и воспитание человека в духе сознательного и ответственного выбора это не одно и то же. По этой причине смешение или совмещение данных целей в уголовном праве противоречит целям правового регулирования и свидетельствует о правовом патернализме, несовместимом с предназначением и возможностями права в целом и уголовного права в частности. Реализацией свободы вовне является поступок человека, представляющий собой результат сознательного выбора одного из множества вариантов поведения индивида как разумного существа. Следовательно, сами по себе осознаваемые личностью варианты поведения, в том числе и преступные, не вышедшие за пределы ее мыслительной деятельности, то есть не воплотившиеся в поступке, ни при каких условиях не могут объявляться преступными. Отсюда авторы еще раз подчеркивают, что возникновение и обнаружение умысла на совершение преступления безразличны уголовному закону и вне сферы его действия. Свобода как выбор, воплощающийся в поступке человека, обеспечивается закреплением в уголовном праве норм, направленных на охрану внешней свободы. Последняя через уголовный закон юридически гарантирует индивиду возможность беспрепятственного передвижения, выбора места жительства, места пребывания, выступая в этом качестве предпосылкой реализации свободы в ее антропологическом измерении. При этом наиболее ярко свобода человека проявляет себя в признаке вины, являющемся обязательным признаком любого состава преступления - единственного основания уголовной ответственности и тем самым наиболее серьезных правоограничений личности. Следует отметить, что принцип вины (ответственности за вину) закреплен уголовным законом (ст. 5) в числе фундаментальных принципов отрасли. С учетом ст. 5 УК РФ уголовная ответственность возможна только при наличии вины как сознательно-волевого отношения человека к содеянному и его последствиям. Такое же отношение присутствует только в случае наличия у человека свободы воли, в реальной возможности регулирования и контроля своего поведения.
\end{abstract}

Ключевые слова: свобода, свобода выбора, свобода воли, уголовный закон, общественно опасное поведение, криминализация, вина.

Пожалуй, одним из наиболее часто употребляемых понятий философского и в целом гуманитарного знания является категория человеческой свободы. Как справедли- во отмечается исследователями, «свобода в пределах философской рефлексии обычно задается как одно из самых трудоемких и проблематичных понятий и скорее предстает в 
виде собрания парадоксов, чем стройного и ясного концепта» [Гаспарян 2011, 6]. При этом автор является далеко не первым, кто подмечает сложность феномена свободы и многовариантность его понимания. О различных трактовках этого термина еще в конце XVIII в. размышлял А. Фергюсон [Фергюсон 2000, 232]. Это же подчеркивал и Ш. Монтескье [Монтескье 2018, 183-184]. Тем не менее, если попытаться сформулировать самое общее определение свободы, то последняя предстает как «возможность не связанного ничем выбора, решения, не зависимого ни от кого, ни от какой внешней силы, в том числе государственно-политической» [Алексеев 2010, VII, 90].

Из такого определения свободы, безусловно приблизительного и в значительной мере пробельного, вытекают следующие ее наиболее значимые сущностные признаки.

Бытие каждого человека не является изолированным - каждый человек встроен в общество и каждый человек «биологичен», несет в себе отпечаток природного начала. Отсюда свобода начинается там, где человек вырывается из круга своих причинно-следственных взаимодействий. В связи с этим, прежде всего, в гегелевской концепции свободы, последняя - так называемая «субстанциональная свобода» - начинается тогда, когда человек «способен преодолеть свое природное начало и осознать свою самость» [Белякова 2009, 255].

Таким образом, «никем не ограниченная и ни от чего не зависимая деятельность кого-либо в конкретной сфере бытия» составляет сущность человеческой свободы [Деев 2001, 88]. Это проявляется в отсутствии каких-либо внешних связей, налагающих на деятельность человека ограничения и детерминирующих ее, и, видимо, объясняет то, что свобода всегда индивидуальна. Как справедливо замечает В.М. Межуев, свобода «...есть выход индивида за пределы своего наличного бытия, своей временности и конечности, непрерывный процесс его трансцендирования в область новых возможностей и более широких горизонтов» [Межуев 2010, 58]. Формой такого «выхода», «бытием» свободы, как полагает С.В. Димитрова, выступает акm творения, или поступок, который в противо- вес действию «находится вне причинно-следственных связей» [Димитрова 2010, 104].

Явлению свободы чужда какая-либо заданность и обусловленность поведения человека, поэтому в ситуации истинной свободы у индивида всегда наличествует выбор нескольких вариантов поведения. Отсутствие выбора и своего рода предопределенность, или обусловленность, поступка свободу абсолютно исключают.

Но при таком понимании свобода отнюдь не равнозначна эгоизму, разнузданности и анархии. В отличие, например, от вседозволенности, высшее проявление свободы - это умение обуздать свои чувства, эмоции, страсти, поставив их под контроль собственного разума [Исмаилов 2009, 138].

В философии И. Канта, глубоко обосновавшего основные аксиологические и антропологические характеристики свободы, величайшая свобода - это пространство активности, состязания, конкуренции и борьбы с целью развития рода человеческого, а стало быть, неотъемлемый спутник свободы и ее проявление - это и людской антагонизм, разобщенность. Последние же явления ставят вопрос о границах свободы, для того чтобы свобода одного была бы совместима со свободой всех других людей. «Государственный строй, - писал мыслитель, - основанный на наибольшей человеческой свободе согласно законам, благодаря которым свобода каждого совместима со свободой всех остальных..., - есть во всяком случае необходимая идея, которую следует брать за основу при составлении не только конституции государства, но и всякого отдельного закона...» [Кант 1998, 408-409]. Лучше всего границы свободы обеспечиваются позитивным правом, поскольку только праву присуща формальная определенность, нормативность, императивность, государственная обеспеченность и общеобязательность в противовес иным регуляторам человеческого поведения, которые не обладают такой совокупностью свойств. Эти границы, как это ни парадоксально, - это гарантия свободы. Как остроумно было замечено В.С. Нерсесянцем, «свобода приходит в мир и утверждается в нем в невидимом, но прочном одеянии права» [Hерсесянц 1997, 24]. 
Таким образом, отмеченное И. Кантом глубинное предназначение права - быть средством обеспечения свободы человека через очерчивание ее границ, позволяющих юридически гарантировать свободу каждого члена общества, имеет принципиальное значение для определения содержания права в целом и каждой его отрасли, его института и его нормы в частности. Отсюда содержание права в целом и любой его отрасли должно всегда определяться основным предназначением права быть юридическим обеспечением, государственно-властной гарантией свободы через четкое определение границ человеческой активности, за пределами которых происходит вырождение свободы в своеволие, анархию и хаос и свобода одного уже не сочетается со свободой других.

Непосредственное отношение эти размышления имеют и к праву уголовному, поскольку именно оно исторически возникает в первую очередь, предшествует возникновению норм иной отраслевой принадлежности и поначалу исчерпывает собой все содержание права того или иного общества и государства. Таким образом, основное предназначение всего позитивного права - гарантировать свободу человека - должно влиять и на содержание уголовного закона. В свою очередь, его содержание определяется в ходе первичных (кодификации) и вторичных (между кодификациями) криминализаций деяний, заключающихся в выявлении общественно опасных форм индивидуального поведения, на которые допустимо, возможно и целесообразно уголовно-правовое воздействие с последующим законодательным объявлением их преступными и наказуемыми [Коробеев 1987, 59].

Размышляя о криминализации с целью улучшения данного магистрального направления уголовно-правовой политики, криминалисты обычно выделяют такие ее составляющие, как причины, основание и принципы, критерии криминализации (криминообразующие признаки) [Лопашенко 2019, 247, 249, 262]. При этом основанием последней совершенно справедливо мыслится существование общественно опасного поведения [Лопашенко 2019, 249]. Рассуждая же о последнем, авторы обычно не выходят за рамки констатации того, что такое поведение представляет собой нарушение разделяемых всем обществом ценностей [Рожнов 2017, 41]. Вместе с тем с учетом сказанного выше содержание общественной опасности необходимо дополнить и тем, что соответствующий вид поведения несет в себе угрозу человеческой свободе.

Надо отметить, что разделяемые тем или иным обществом ценности, определяемые уровнем его экономического развития, культурной, нравственной зрелости, задают как раз границы и объем его свободы, которые у различных государств могут и не совпадать, как могут они не совпадать и у одного и того же общества (государства, народа) на разных этапах его исторического развития. Отсюда опасным является не посягательство на ценности само по себе, а посягательство на свободу человека через нарушение сложившейся в социуме системы ценностей. Таким образом, основанием криминализации, определяющей содержательный облик уголовного закона (большинства его норм), является индивидуальное общественно опасное поведение, делающее невозможным в силу существующей угрозы своей повторяемости и массовидности реализацию свободы каждого члена человеческого общества .

Думается, именно такое понимание оснований криминализации в контексте понимания всего позитивного права как государственно обеспеченной гарантии человеческой свободы позволяет иначе взглянуть на проблему легитимности уголовного закона, которая в общем виде может быть определена как общественное одобрение (согласие, признание) какого-либо политико-правового явления, состояния, института, процесса и проч. и которая, по сути, равнозначна требованию справедливости в ее государственно-правовом измерении [Вопленко 2010, 12].

Однако помимо того, что всеобщая человеческая свобода и (что одно и то же!) индивидуальная свобода каждого обязывает для достижения цели своей обеспеченности уголовный закон быть легитимным и справедливым, она же и требует от уголовного закона быть предупредительным и деликатным. И связано это с тем, что, прежде всего, уголовное право очерчивает крайние границы человеческого поведения, отделяет наиболее опасные 
формы поведения от всех других социальных девиаций (в том числе и правонарушающих, а также и аморальных, нейтральных, полезных). Отсюда оно способно защитить человеческую свободу, но не может и не должно заставлять кого бы то ни было быть свободным. Никакое позитивное право, включая и уголовное, не может воспитать свободу или научить человека быть свободным!

Фактически понятийный ценностный ряд феномена свободы включает в себя и независимость личности, что вполне понятно из вышеприведенных характеристик свободы только вырываясь за границы довлеющих над ним связей и постановляя себя в ситуацию ничем и никем не ограничиваемого выбора, человек становится свободным. Таким образом, независимость личности - и составной элемент, и предпосылка, и, в известном смысле, синоним свободы. «Мысль о естественно-природном характере идеи свободы и ее сущностной конкретизации в независимости личности, - пишет Н.Н. Вопленко, - достаточно четко и последовательно проходит в большинстве исследований этой проблемы». Он же замечает, что «современное понимание свободы как бы поглощает собой понятие независимости, сообщая ей цивилизованный характер» [Вопленко 2017, 55]. Разумеется, независимость личности несовместима с правовым патернализмом. Как правильно замечено Э.Ю. Соловьевым, «пресекая наиболее опасные формы зла, право одновременно... стоит на страже добровольно выбираемого добра» [Соловьев 1991, 405]. При этом право защищает свободу, устанавливая не только как бы предельные границы человеческой активности, за которыми уже начинается несвобода или свобода одного превращается в несвободу другого, но и заслоны «против попыток принудительного осчастливливания и принудительного совершенствования людей» [Соловьев 1991, 405].

Думается, ничем иным, как проявлением патернализма в тоталитарном государстве, было длительно сохранявшееся существование в советском уголовном праве уголовноправового запрета добровольных мужских гомосексуальных связей в ч. 1 ст. 121 УК РСФСР 1960 г., пока Законом РФ от 29 апреля 1993 г. № 4901-1 «О внесении изменений и дополнений в Уголовный кодекс РСФСР, Уголовно-процессуальный кодекс РСФСР и Исправительно-трудовой кодекс РСФСР» данная статья не была изложена в новой редакции, согласно которой преступными объявлялись только насильственные (и к ним приравненные) формы такого рода удовлетворения половой страсти.

Другим примером государственно-властной попытки заставить человека стать лучше с помощью мер уголовной репрессии была ч. 1 ст. 127 УК РСФСР 1960 г., просуществовавшая 36 лет вплоть до прекращения действия советского Кодекса 1 января 1997 г., объявлявшая преступным неоказание лицу, находящемуся в опасном для жизни состоянии, необходимой и явно не терпящей отлагательства помощи, а равно и несообщение надлежащим учреждениям или лицам о необходимости оказания такой помощи. Субъектом ответственности по ч. 1 ст. 127 УК РСФСР являлись любые вменяемые лица, достигшие 16-летнего возраста, которые заведомо могли оказать упомянутую помощь без серьезной опасности для себя или других лиц, безотносительно к их правовым (работники социальных служб), родственным (дети, родители и т. д.) или фактическим связям с потерпевшим.

Видимо, воспринятие естественно-правовой концепции государства и права, переосмысление его роли в жизни социума, новый трезвый взгляд на его (право вообще и уголовное право в частности) возможности и «границы допустимости», «границы влияния» привели к тому, что в принятом в 1996 г. и ныне действующем УК России круг субъектов, ответственных за неоказание помощи (ст. 125), был значительно сужен и ограничен исключительно только лицами, обязанными заботиться о потерпевшем или поставившими его в опасное для жизни или здоровья состояние.

Итак, право в своем ценностно-онтологическом измерении предназначено для обеспечения свободы, но оно не может предопределить вектор развития личности, направить, например, развитие личности в сторону свободы и ответственного выбора.

Описывая свободу, ученые обычно оперируют понятиями выбора, разума, независи- 
мости, личности, индивидуальности и т. п. Последнее указывает на то, что свобода - это феномен, в первую очередь, (само)сознания, воплощаемый в человеческих поступках. Из такого понимания свободы вытекают два важных для уголовного права следствия.

Во-первых, право вообще регулирует объективированное вовне поведение человека, его «наличное бытие». Соответственно и право уголовное является регламентацией либо правопослушного поведения, к которому субъекты понуждаются через систему запретов и виды ответственности за их нарушение (в терминологии Н.А. Лопашенко - охранительно-предупредительные отношения), либо того поведения, которое следует уже за нарушением уголовно-правового запрета (уголовно-регулятивные отношения) [Лопашенко 2019, 26-27]. Отсюда право, включая и уголовное, в принципе не может влиять на мысли, чувства, намерения, мотивы, цели и т. д., еще не вышедшие за пределы сферы сознания, не воплотившиеся в деянии как внешней, материальной «оболочке» поступка.

Именно этим, например, объясняется то, что принципиально ненаказуемой в отечественном уголовном праве является такая стадия совершения преступления, как возникновение и обнаружение умысла, «замышление» преступления. Исходя из этих соображений, небесспорным видится нам целесообразность сохранения в действующем УК РФ такого состава преступления, как обещание или предложение посредничества во взяточничестве (ч. 5 ст. 291.1 УК РФ), потому что такое обещание или предложение является частным случаем обнаружения умысла, не переросшего, однако, во внешне выраженный акт поведения, который может подлежать какому бы то ни было правовому воздействию.

Во-вторых, в тех же случаях, когда неким проявлениям (само)сознания, его ценностно-ориентационному сегменту уголовный закон придает качество юридического факта, мы имеем дело с правовой презумпцией. При этом наличие такой презумпции подтверждается условиями, устанавливаемыми в уголовном законе и поддающимися объективной проверке. Так, в соответствии с ч. 1 ст. 75 УК РФ лицо, впервые совершившее преступление небольшой или средней тяжести, может быть освобождено от уголовной ответственности, если оно вследствие деятельного раскаяния перестало быть общественно опасным. Поскольку деятельное раскаяние - это исключительно сфера личностного пространства индивида, куда в принципе невозможно проникнуть извне, судить о его наступлении возможно только лишь по тем внешним актам поведения человека, которые могут засвидетельствовать такого рода его психическое отношение к совершенному негативному поступку: явка с повинной, способствование раскрытию и расследованию преступления, возмещение ущерба или иное заглаживание причиненного преступлением вреда. Вместе с тем презумпция потому и является презумпцией, что это некое допущение, условность, предположение. Исследователи проблематики данного основания освобождения от уголовной ответственности справедливо, на наш взгляд, отмечали, что «обозначенные в законе формы положительного посткриминального поведения... фактически могут служить средством достижения различных целей, в том числе таких, стремление к которым не исключает повторения преступления» [Алюшкин 2001, 11-12] и сохранения лицом своей общественной опасности.

Помимо того, что свобода как ценность определяет содержание уголовно-правовых запретов, законодательную оценку индивидуального поведения как общественно опасного, задает конкретную направленность уголовно-правового регулирования, она же находит свое отражение в уголовном праве и в более утилитарной, «приземленной» форме. Выше мы сделали акцент на внутренней свободе человека, суть которой состоит в стремлении к деятельности, вырывающейся за границы обыденности и повседневности, когда такая деятельность предопределяется возможностью осознанного, разумного выбора в соответствии со своими намерениями и интересами. Вместе с тем «реализация этой внутренней свободы человека может осуществляться только благодаря объективной возможности для такой деятельности или внешней свободе» [Исмаилов 2009, 137].

Защите и обеспечению внешней свободы человека в действующем УК России посвящены ст. 126-128 гл. 17 «Преступления 
против свободы, чести и достоинства личности», в которых описаны такие конструкции преступлений, в которых свобода человека выступает основным непосредственным объектом уголовно-правовой охраны. При этом в Особенной части УК РФ имеется множество и таких составов преступных деяний, в которых посягательство на свободу человека выступает способом нарушения иных благ, составляющих предмет волевых устремлений преступника, в силу чего свобода человека предстает в них либо дополнительным обязательным (ст. 206, 301), либо дополнительным факультативным объектом преступления (ч. 2 ст. 305).

Свобода человека в отраслевой литературе при раскрытии объекта названных выше преступлений определяется как право на «свободное передвижение человека, возможность выбора им места жительства и пребывания, а также возможность поступать в соответствии со своей волей без какого-либо принуждения извне в любой сфере жизнедеятельности» [Марахтанова 2006, 8]. Безусловно, свобода в значении «охраняемого уголовным законом блага» - это отнюдь не та свобода, которая в философской литературе предстает как объект исследования аксиологии и антропологии, поскольку свобода в ее ценностном измерении несводима только к выбору человеком своего места пребывания в пространственно-временных координатах. Между тем личная свобода, свобода в физическом смысле, телесная свобода является предпосылкой реализации той многомерной природной свободы, которая отличает человека от всех других живых существ и служит залогом его активности, самореализации.

Однако характеристика свободы, выступающей объектом охраны для норм уголовного права, будет неполной, если не упомянуть и те виды преступного поведения, сущность которых состоит не в посягательстве на телесную свободу человека, а в игнорировании человеческого выбора при решении вопросов пользования тем или иным гарантированным законом благом, а равно в существенном сужении и даже исключении для потерпевшего свободы выбора линии его поведения.

Условно такие посягательства возможно разделить на две группы.
Первую группу составят некоторые преступления, собранные законодателем в гл. 18 «Преступления против половой неприкосновенности и половой свободы личности» действующего УК РФ, которые также можно подразделить на две подгруппы:

- насильственные посягательства на половую свободу человека, объектом которых являются отношения, обеспечивающие свободу выбора полового партнера и формы удовлетворения половой страсти (ст. 131, 132 УК РФ за исключением п. «а» ч. 3, п. «б» ч. 4, ч. 5 каждой из этих статей УК);

- ненасильственные посягательства на те же охраняемые УК РФ ценности (ст. 133 УК).

Иные преступления данной главы, потерпевшими от которых называются лица, не достигшие 16-летнего возраста, относятся, по нашему мнению, к посягательствам на половую неприкосновенность личности. Связано это с тем, что право распоряжаться своей свободой вообще и половой свободой в частности возможно только при условии достижения человеком определенного уровня социальной, культурной и нравственной зрелости, которая, в свою очередь, обычно презюмируется и увязывается со взрослением лица, с достижением им определенного возраста (так называемого «возраста согласия»).

Ко второй группе посягательств против свободы, понимаемой в значении свободы самостоятельного, осознанного и ни от кого не зависимого выбора варианта поведения, относятся все преступления, в структуре объективной стороны которых действие либо способ совершения преступления выражен принуждением (как правило, альтернативно с другими действиями или способами): ст. 120, п. «а» ч. 2 ст. 141 , ч. 2 ст. 142 , ст. $144,147,149$, 179 , ч.ч. 1,2 ст. 184 , ч. 2 ст. 185.5 , ст. $240,283.1$, 302 , ч.ч. 2-4 ст. 309, ст. 333 УК РФ.

При этом размышления о свободе, присутствующей в нормах уголовного права и предопределяющей его содержание, будут явно неполными, если мы не выскажемся о «святая святых» отрасли - о составе преступления, который в силу прямого указания ст. 8 УК РФ является единственным основанием уголовной ответственности. Как же феномен свободы находит свое отражение в признаках состава преступления и находит ли вообще? 
Думается, на последний вопрос необходимо дать однозначно положительный ответ, поскольку без свободы в изложенном выше понимании наличия (в числе прочего) у человека возможности осознанного выбора одного из нескольких возможных вариантов своего поведения (один из которых может повлечь за собой и преступные последствия) в принципе невозможна уголовная ответственность. Свобода в теоретическом осмыслении и законодательном регулировании состава преступления является необходимым атрибутом таких его признаков, как деяние (признак объективной стороны) и вина (признак субъективной стороны). При этом принцип вины (ответственности за вину) возведен в действующем Кодексе в ранг основополагающих принципов отрасли (ст. 5 УК).

Обычно, раскрывая понятие вины, отечественные криминалисты определяют его как «психическое отношение лица к совершаемому им общественно опасному деянию, предусмотренному уголовным законом, и к его общественно опасным последствиям» [Рарог $2015,53]$. Психическое отношение человека к окружающей его реальности, отличающее его от психики животных, состоит в наличии у человека сознания, представляющего собой «высшую функцию мозга, заключающуюся в обобщенном и целенаправленном отражении действительности, в предварительном мысленном построении действий и предвидении их результатов, в регулировании и самоконтроле поведения человека» [Скляров 2004, 12]. Прямым следствием наличия у психики человека указанного свойства является «возможность свободного выбора при конфликте желаний, способность к самодетерминации и саморегуляции человеком своей деятельности» [Скляров 2004, 12], или наличие воли.

Таким образом, если сознание, оценивая и исследуя, формирует образ поведенческого акта, который пока только остается мысленной моделью субъекта и не более того, то воля переводит идеальный образ в реальную действительность, воплощаясь в конкретном, внешневыраженном поступке индивида.

Следовательно, «переводя» специальную терминологию отрасли на язык философских категорий, можно сказать, что вина - это осознанное и волевое отношение человека $\kappa$ своему поступку, при котором у лица наличествует несколько вариантов поведения (включая и противоправный), но при этом, основываясь на своих ценностных ориентирах, интересах и иелях, особенностях сложившейся ситуации, человек совершает поступок, запрещенный уголовным законом. В связи с этим, если у человека отсутствует свобода выбора и его поступок кемто предопределен, но не им самим, свобода воли (или даже сама воля) исключается. Последнее же обстоятельство исключает вину и ответственность.

Отсюда при ее выпадении из структуры человеческого поведения свобода воли, понимаемая как, по сути, синоним свободы выбоpa [Москаленко 2013, 124], будучи элементом свободы вообще, ее сущностным признаком, исключает и наличие самой свободы.

В уголовном праве находит отражение не только феномен свободы, но и его антипод, обозначенный понятием, парным для изучаемого [Толченкин, Толченкина 2016, 64]. Наиболее наглядно диалектика свободы и несвободы проявляется в институте наказания. Последнее по своей сути есть мера несвободы. Карательное содержание любого вида наказания выглядит как определенный набор ограничений свободы. В некоторых случаях это находит отражение в наименовании вида наказания (ограничение свободы, лишение свободы на определенный срок, пожизненное лишение свободы). При этом даже в таких видах наказания несвобода не является абсолютной. В условиях изоляции в исправительном учреждении человек остается свободной личностью, то есть имеющей определенный комплекс прав и свобод, хотя и несколько урезанный, но подлежащий государственной защите.

\section{СПИСОК ЛИТЕРАТУРЫ}

Алексеев 2010 - Алексеев С.С. Собрание сочинений. В 10 т. [+ справоч. том]. М.: Статут, 2010.

Алюшкин 2001 - Алюшкин П.В. Фактический состав освобождения от уголовной ответственности в связи с деятельным раскаянием: автореф. дис. ... канд. юрид. наук. Казань, 2001.

Белякова 2009 - Белякова Л.Ю. Проблематика свободы в образовательном пространстве в классической немецкой философии // Личность. 
Культура. Общество. 2009. Т. 11, № 1 (46-47). C. 251-257.

Вопленко 2010 - Вопленко Н.Н. Понятийный ряд теории справедливости // Вестник Волгоградского государственного университета. Серия 5 , Юриспруденция. 2010. № 2 (13). С. 6-17.

Вопленко 2017 - Вопленко Н.Н. Свобода и справедливость: закономерности взаимодействия // Юридическая справедливость: проблемы теории и практики: коллектив. моногр. Волгоград: Изд-во ВолГУ, 2017.

Гаспарян 2011 - Гаспарян Д.Э. Предисловие // Философия свободы: коллектив. моногр. СПб.: Алетейя, 2011.

Деев 2001 - Деев А.Н. Введение в теорию гармонии. Новосибирск: Сиб. Хронограф, 2001.

Димитрова 2010 - Димитрова С.В. Онтологическое трансцендирование (условия обретения свободы) // Вестник Волгоградского государственного университета. Серия 7, Философия. 2010. № 1(11). С. 103-108.

Исмаилов 2009 - Исмаилов Н.О. Справедливость как мера свободы // Социология власти. 2009. № 7. C. 136-144.

Кант 1998 - Кант И. Критика чистого разума. Минск: Литература, 1998.

Коробеев 1987 - Коробеев А.И. Советская уголовно-правовая политика: проблемы криминализации и пенализации. Владивосток: Изд-во Дальневосточ. ун-та, 1987.

Лопашенко 2019 - Лопаменко Н.А. Размышления об уголовном праве. Уголовное право. Уголовная ответственность. Уголовная политика. Авторский курс: монография. М.: Юрлитинформ, 2019.

Марахтанова 2006 - Марахтанова Е.А. Преступления против свободы личности: вопросы законодательной регламентации и квалификации: автореф. дис. ... канд. юрид. наук. Самара, 2006.

Межуев 2010 - Межуев В.М. Философия как самосознание человека в свободе // Идеи и идеалы. 2010. Т. 1. № 3 (5). С. 53-61.

Монтескье 2018 - Монтескье Ш. О духе законов. М.: РИПОЛ классик, 2018.

Москаленко 2013 - Москаленко Д.Н. Свобода выбора и свобода воли: грани соприкосновения // Исторические, философские, политические и юридические науки, культурология и искусствоведение. Вопросы теории и практики. 2013. № 4 (30). В 3 ч. Ч. 3. С. 123-127.

Нерсесянц 1997 - Нерсесяни В.С. Философия права: учебник для вузов. М.: ИНФРА-М: НОРМА, 1997.

Рарог 2015 - Рарог А.И. Проблемы квалификации преступлений по субъективным признакам: монография. М.: Проспект, 2015.
Рожнов 2017 - Рожнов А.П. Нужна ли российскому праву категория общественной опасности? // Legal Concept = Правовая парадигма. 2017. T. 16, № 3. C. 38-42. DOI: https://doi.org/ 10.15688/lc.jvolsu.2017.3.6.

Скляров 2004 - Скляров С.В. Вина и мотивы преступного поведения. СПб.: Юрид. центр Пресc, 2004.

Соловьев 1991 - Соловьев Э.Ю. Прошлое толкует нас: очерки по истории философии и культуре. М.: Политиздат, 1991.

Толченкин, Толченкина 2016 - Толченкин Д.А., Толченкина М.Э. Диалектика свободы и несвободы как проблема юридической науки // Юрид. наука. 2016. № 6. С. 62-66.

Фергюсон 2000 - Фергюсон А. Опыт истории гражданского общества: пер. с англ. М.: Рос. полит. энцикл., 2000.

\section{REFERENCES}

Alekseev S.S., 2010. Collected Works. In 10 vols. [+ Reference volume]. Moscow, Statut.

Alyushkin P.V., 2001. The Actual Composition of the Exemption from Criminal Liability in Connection with Active Repentance. Candidate of Sciences. jurid. sci. abs. diss. Kazan.

Belyakova L.Yu., 2009. Problems of Freedom in Educational Space in Classical German Philosophy. Lichnost. Kultura. Obshchestvo, vol. 11, no. 1 (46-47), pp. 251-257.

Voplenko N.N., 2010. Conceptual Series of the Theory of Justice. Vestnik Volgogradskogo gosudarstvennogo universiteta. Seriya 5, Yurisprudenciya, no. 2 (13), pp. 6-17.

Voplenko N.N., 2017. Freedom and Justice: Patterns of Interaction. Yuridicheskaya Spravedlivost: Problemy Teorii i Praktiki: kollektiv. monogr. Volgograd, Izd-vo VolGU.

Gasparyan D.E., 2011. Preface. Filosofiya svobody: kollektiv. monogr. Saint Petersburg, Aleteiya.

Deyev A.N., 2001. Introduction to the Theory of Harmony. Novosibirsk, Sibirskiy Hronograf.

Dimitrova S.V., 2010. Ontological Transcendence (Conditions of Gaining Freedom). Vestnik Volgogradskogo gosudarstvennogo universiteta. Seriia 7, Filosofiia, no. 1 (11), pp. 103-108.

Ismailov N.O., 2009. Justice as a Measure of Freedom. Sociologiia vlasti, no. 7, pp. 136-144.

Kant I., 1998. Criticism of Pure Reason. Minsk, Literatura.

Korobeev A.I., 1987. Soviet Criminal Law Policy: Problems of Criminalization and Penalization. 
Vladivostok, Izd-vo Dalnevostochnogo universiteta.

Lopashenko N.A., 2019. Reflections on Criminal Law. Criminal Law. Criminal Liability. Criminal Policy. Author's Course: Monograph. Moscow, Yurlitinform.

Marahtanova E.A., 2006. Crimes Against Individual Freedom: Issues of Legislative Regulation and Qualifications. Candidate of Sciences. jurid. sci. abs. diss. Samara.

Mezhuev V.M., 2010. Philosophy as a Person's SelfAwareness in Freedom. Idei i idealy, vol. 1, no. 3 (5), pp. 53-61.

Monteskye Sh., 2018. About the Spirit of Laws. Moscow, RIPOL classik.

Moskalenko D.N., 2013. Freedom of Choice and Free Will: the Verge of Contact. Istoricheskie, filosofskie, politicheskie i yuridicheskie nauki, kul'turologiya $i$ iskusstvovedenie. Voprosy teorii i praktiki, no. 4 (30), in 3 parts, part 3, pp. 123-127.
Nersesyants V.S., 1997. The Philosophy of Law. Moscow, INFRA-M, NORMA.

Rarog A.I., 2015. Problems of Qualification of Crimes on Subjective Grounds: a Monograph. Moscow, Prospekt.

Rozhnov A.P., 2017. Does Russian Law Need a Category of Public Danger? Legal Concept $=$ Pravovaya paradigma, vol. 16, no. 3, pp. 38-42. DOI: https://doi.org/10.15688/lc.jvolsu.2017.3.6

Sklyarov S.V., 2004. Guilt and Motives of Criminal Behavior. Saint Petersburg, Yuridicheskij centr Press.

Solovyev E.Yu., 1991. The Past Interprets Us: Essays on the History of Philosophy and Culture. Moscow, Politizdat.

Tolchenkin D.A., Tolchenkina M.E., 2016. Dialectics of Freedom and Unfreedom as a Problem of Legal Science. Yuridicheskaya nauka, no. 6, pp. 62-66.

Fergyuson A., 2000. Experience in the History of Civil Society. Moscow, Rossijskaya politicheskaya enciklopediya.

\section{Information About the Authors}

Lyubov V. Lobanova, Doctor of Sciences (Jurisprudence), Professor, Head of the Department of Criminal Law, Volgograd State University, Prosp. Universitetsky, 100, 400062 Volgograd, Russian Federation, up@volsu.ru, lobanova@volsu.ru, https://orcid.org/0000-0002-4686-124X

Alexey P. Rozhnov, Candidate of Sciences (Jurisprudence), Associate Professor, Department of Criminal Law, Volgograd State University, Prosp. Universitetsky, 100, 400062 Volgograd, Russian Federation, rozhnov@volsu.ru, https://orcid.org/0000-0001-5465-6978

Larisa N. Larionova, Candidate of Sciences (Jurisprudence), Associate Professor, Department of Criminal Law, Volgograd State University, Prosp. Universitetsky, 100, 400062 Volgograd, Russian Federation, larionova@volsu.ru, https://orcid.org/0000-0002-8243-1167

\section{Информация об авторах}

Любовь Валентиновна Лобанова, доктор юридических наук, профессор, заведующая кафедрой уголовного права, Волгоградский государственный университет, просп. Университетский, 100, 400062 г. Волгоград, Российская Федерация, up@volsu.ru, lobanova@volsu.ru, https://orcid.org/0000-0002-4686-124X

Алексей Петрович Рожнов, кандидат юридических наук, доцент кафедры уголовного права, Волгоградский государственный университет, просп. Университетский, 100, 400062 г. Волгоград, Российская Федерация, rozhnov@volsu.ru, https://orcid.org/0000-0001-5465-6978

Лариса Николаевна Ларионова, кандидат юридических наук, доцент кафедры уголовного права, Волгоградский государственный университет, просп. Университетский, 100, 400062 г. Волгоград, Российская Федерация, larionova@volsu.ru, https://orcid.org/0000-0002-8243-1167 